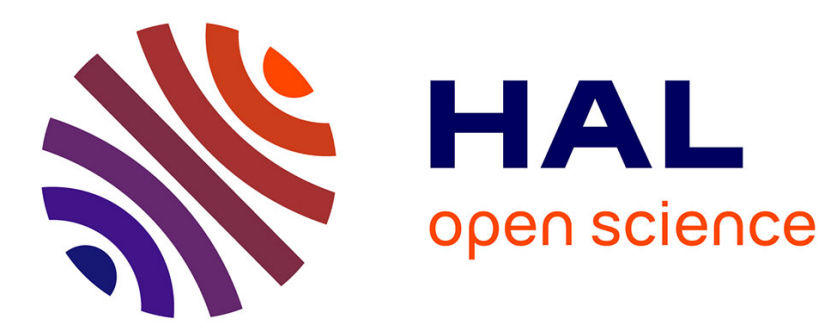

\title{
Has China Replaced Colonial Trade?
}

\author{
Laurent Didier, Pamina Koenig
}

\section{To cite this version:}

Laurent Didier, Pamina Koenig. Has China Replaced Colonial Trade ?. 2016. halshs-01397801

\section{HAL Id: halshs-01397801 https://shs.hal.science/halshs-01397801}

Preprint submitted on 16 Nov 2016

HAL is a multi-disciplinary open access archive for the deposit and dissemination of scientific research documents, whether they are published or not. The documents may come from teaching and research institutions in France or abroad, or from public or private research centers.
L'archive ouverte pluridisciplinaire HAL, est destinée au dépôt et à la diffusion de documents scientifiques de niveau recherche, publiés ou non, émanant des établissements d'enseignement et de recherche français ou étrangers, des laboratoires publics ou privés. 


\section{PARISSCHOOL OF ECONOMICS}

WORKING PAPER Nº $2016-23$

Has China Replaced Colonial Trade?

Laurent Didier

Pamina Koenig

JEL Codes: F1, F54

Keywords: colonial trade, gravity equation, China, multilateral resistance, bilateral effects

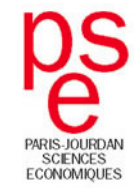




\title{
Has China Replaced Colonial Trade ? *
}

\author{
Laurent Didier ${ }^{\dagger} \quad$ Pamina Koenig ${ }^{\ddagger}$
}

November 15, 2016

\begin{abstract}
China is often suspected of taking over the extraordinary trade relationships that former colonies had within colonial empires. We detail the three reasons why China's trade flows with former colonies could exhibit unexpected levels after independence. Besides potential preferential bilateral relationships built after independence, the two expected determinants of trade flows are China's export capacity and the natural redirection caused by the increase in country pairs trade costs due to independence. We investigate and quantify the three reasons explaining the level of former colonies' trade flows with China. Using sequentially naive graphical representations and structural gravity equations, we show that methodological issues can be largely responsible for displaying and estimating abnormaly high trade levels between former colonies and China. We show that increased trade between these pairs of countries is the result of coinciding unilateral factors on each side which raise trade with all partners, instead of being driven by more intense bilateral preferences. We then measure the reorientation of trade flows from former colonies' metropoles towards China and show that independence has produced the expected redistribution: trade flows would be $15 \%$ lower with China, had former colonies not become independent.
\end{abstract}

\section{JEL Codes: F1, F54.}

Keywords: colonial trade, gravity equation, China, multilateral resistance, bilateral effects

\section{Introduction}

Given its spectacular increase during the second half of the twentieth century, there is nothing surprising to the extensive coverage on Chinese trade by the press and its large documentation by government agencies 1 . While evident reasons for the surge of Chinese trade come to mind,

${ }^{*}$ We thank Keith Head and Thierry Mayer for making their data and code available on their gravity handbook website (https://sites.google.com/site/hiegravity/).

${ }^{\dagger}$ CEMOI University of La Reunion, 15 avenue Rene Cassin, 97400 St Denis. didier.laurent3@hotmail.com

${ }^{\ddagger}$ University of Rouen \& Paris School of Economics, 48 boulevard Jourdan 75014 Paris. pamina.koenig@psemail.eu

${ }^{1}$ In the Financial Times' featured themes for example, the word 'trade' is four times associated to a country's name, and China is one of those. The others ones are the UK, the US, the EU: http://www.ft.com/topics/ themes 
related to its transition towards a market economy (Storesletten and Zilibotti (2014), Keller et al. (2013)), followed by policy changes in 1992 and the country's rise as a center for production for foreign markets (Autor et al. (2013)), the press insists on relating the increasing share of countries' imports from China to a change in bilateral preferences with the world's first exporter 2 , As China has not been active in signing free trade agreements since WWII, remaining explanations include informal channels like business networks, political convergence or even political influence of China ${ }^{3}$, Conjectures about extraordinary commercial relationships with China are indeed particularly strong in the case of countries which have come out of controlled trade relationships, like former colonies 4 . Any evidence of abnormaly high commerce with the newly independent countries provides material for the claim that China is taking over the specific trade relation that these countries shared with the hegemon. Figure 1, which displays the absolute level of trade between three ex-colonies 5 , and respectively their former colonizer and China, if often interpreted as an impressive catch-up of China with respect to the former colonial power.

In this paper, we use the gravity equation to quantify the three central determinants of China-colonies' trade: traders' size, bilateral connections, and countries' accessibility to all partners. We show that increased trade between these pairs of countries is the result of coinciding unilateral factors on each side which raise trade with all partners, instead of being driven by more intense bilateral preferences. Gravity equations have been used to analyse trade flows since their introduction in economics by Jan Tinbergen in 1962. Although gravity equations highlight three main determinants of trade, the literature mainly focuses on quantifying bilateral factors, be they persistent or reversible. Tariffs and trade agreements are examples of countries' decisions to smooth accessibility among them, and have been investigated among many others by Carrere (2006), Baier and Bergstrand (2007), and most recently by Limão (2016). Longrun determinants of trade flows have been analysed by Melitz and Toubal (2014) (common language), Lewer and Van den Berg (2007) (institutions and religions), or Disdier and Head (2008) (distance).

The three important building blocks of gravity that we investigate all represent a channel possibly leading to the pattern observed in figure 1. The first channel are the sizes of trading economies. China is an extraordinary and growing participant in world production in the post

\footnotetext{
${ }^{2}$ In September 2009 the China Business Review reports "Economic ties between China and India will play a large role in one of the most important bilateral relationships in the world by 2020. Bilateral trade has already surged from under 3 billion USD in 2000 to nearly 52 billion USD in 2008." (http://www. chinabusinessreview. com/china-and-india-greater-economic-integration/)

"How China Uses Trade to Influence the South China Sea", in https://www.stratfor.com/image/ how-china-uses-trade-influence-south-china-sea, or "Is China becoming Africa's new colonial master?", by the BBC in 2012 (http://www.bbc.com/news/world-asia-18901656)

${ }^{4}$ http://www.slate.com/blogs/moneybox/2015/11/24/china_s_role_in_africa_is_exciting_for_china_ but_is_it_as_great_for_africa.html

${ }^{5}$ We choose these three former colonies since they have the advantage of having available data for most years in the sample.
} 
WWII period. This is rarely taken into account in non-academic graphical illustrations of Chinese trade. We first complement figure 1 with the evolution of production for the Chinese economy, and show that the abnormal character of the curve disappears. The observed catch-up seems to be very well explained by the comparative evolution of production and export capacities of the colonizer and China. Once the exporter's capacity is taken into account, the evolution of bilateral China-colonies trade doesn't seem to urgently call for bilateral explanations.

The second channel for trade increase in gravity equations lies in bilateral accessibility terms. We investigate the existence of a change in bilateral links between China and former colonies, using a structural gravity equation. We estimate bilateral China-colonies dummies, representing potential reasons for "excess trade" between these partners after independence. In related papers analyzing the decrease of trade between colonies and their hegemon, Head et al. (2010) and Lavallée and Lochard (2015) also estimate the effect of independence between ex-colonies and a wider group of Rest-of the World partners, and find contrasting results. Head et al. (2010) show that countries that become independent trade in average less with third countries. Lavallée and Lochard (2015) on the contrary find an increase in former colonies' trade flows to the rest of the world. In the case of China, we fail to find any statistically significant effect of independence with the colonies, in particular when using the theory-consistent gravity equation and hence controlling for unilateral and bilateral unobserved determinants of trade. The evolution of former colonies' trade with China during the second half of the nineteenth century is fully explained by the usual gravity determinants, and no bilateral post-independence specificity stands out.

The third channel for trade variation is the indirect effect on all countries in the world, including China, of changes in trade policy and political relations between colonies and the colonizer at independence. This effect operates through "multilateral resistance" terms in the gravity equation, which dispatch the redistribution of trade flows. This effect can only be quantified using trade flows simulations, because predicted trade needs to incorporate the new multilateral resistances resulting from the change of bilateral trade costs. There are few examples in the literature of such simulations taking into account third countries' effects: Glick and Taylor (2010) investigate the direct and indirect costs of military conflict, and Anderson and Yotov (2010) compute the impact of an agreement on the internal trade of Canadian provinces. In our case, former colonies went through an important variation of their main trade costs with the metropole when becoming independent, and therefore represent an interesting case on which to study the reallocation of expenditure. The gravity equation shows that trade naturally redistributes towards all trade partners following such a drastic trade cost change. We quantify this channel by using the structural gravity model to simulate factual trade flows, as well as a counterfactual trade matrix in the scenario where independence would not have happened. The difference between the two simulations provides a measure of how much trade was redirected because of independence, and thus allows to quantify whether the increase in former colonies' 
Figure 1: Imports from colonizer and from China
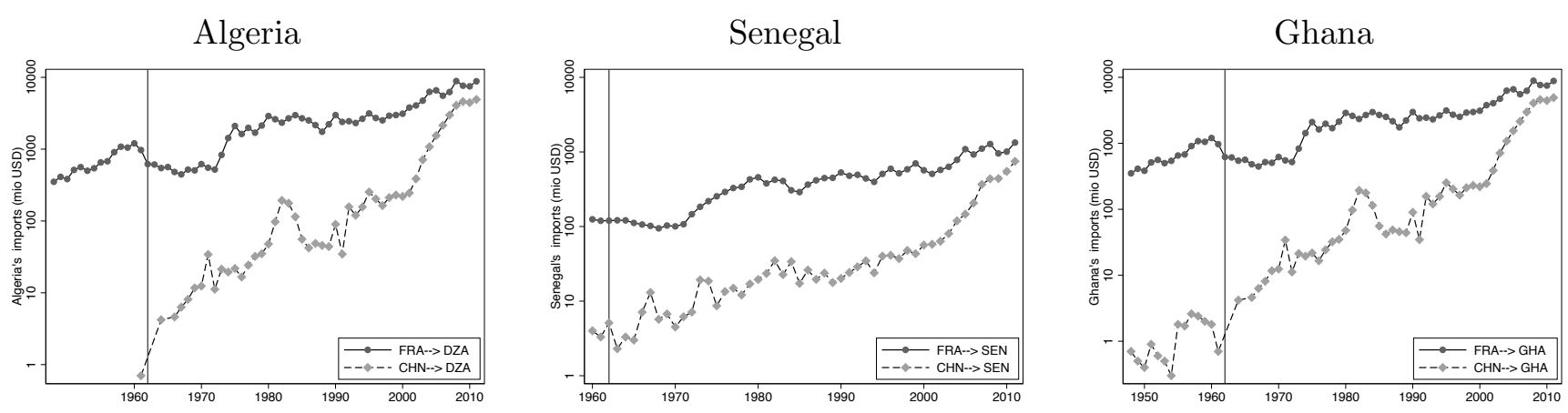

import share from China can be attributed to a change in the multilateral accessibility of all countries. Our results show that in the year 2010, independence increased trade with China by $15 \%$, compared to a hypothetical situation where those countries would have remained colonies until that same year. This result shows that the multilateral resistance terms of the gravity equation play here a central role in explaining the variation of trade flows, whereas they usually are considered as a nuisance term to be controlled in the estimation by the use of fixed-effects. These terms, required for theoretical consistence of the gravity equation, have been central in the renewal of academic interest for this empirical tool (Head and Mayer $(2014)$, Costinot and Rodríguez-Clare (2013)). Our paper shows a case where their inclusion is critical in appropriate understanding of empirical trade patterns.

Our paper shows that out of the three explanations for the surge in former colonies' share of imports from China, only the two reasons related to monadic determinants are in effect. The higher trade shares are not explained by the development of bilateral links involving only China and the ex-colonies. Bilateral factors typically refer to extraordinary reasons to trade in contrast with the ordinary reasons which are the size of partners and their access to other countries. According to our findings, there is nothing exceptional in the level of trade involving China and the former colonized States.

The remainder of the paper is structured as follows. Section 2 presents the data on worldwide trade flows and independence events. Section 3 graphs and estimates the (absence of) specificity of Chinese trade flows with former colonies following independence. In section 4 we compute the counterfactual trade of ex-colonies with China, had the former countries not become independent. Section 5 concludes.

\section{Data}

To estimate whether China's trade with formerly colonized countries shows unexpected trends or level, we primarily use the dataset made available by Head et al. (2010). They compile in 
particular data on countries' trade flows during the second half of the nineteenth century up to 2006, and data on independence years, for all metropoles. After listing the data sources, we illustrate graphically the trade flows that are of interest for us, hence former colonies's trade with their metropole before and after independence, and the same countries with China.

\subsection{Independence and definition of colonies}

Information on the independence dates of countries come from the CIA World Factbook. The raw data extracted by Head et al. (2010) contains the name of countries which have been colonized, the name of the colonizer, and the date of independence. We proceed to two adjustments with respect to the original independence data. First, we retain only the latest independence date for the countries that have been colonized by different colonizers. This allows to keep the date at which sovereignty was effectively achieved. Mauritius, for example, became independent from France in 1810, however it became fully independent in 1968 from the UK. Dropping early independence dates reduces the number of country pairs with colonial histories from 249 to 194, and shifts the beginning of the database from 1710 (when Estonia ceased to be part of Sweden) to 1804 (independence of Hati from France).

Still, the data comprises independence dates in the eighteenth and nineteenth centuries. Our investigation of Chinese commercial relations with former-colonies concentrates on the second part of the nineteenth century, i.e. on countries which gained sovereignty after 1939. This allows to retain the recent transformations of the Chinese economy, and also to let aside the independence dates of the eighteenth and early nineteenth century, whose nature largely differ from the post-WWII context. The first countries to become independent after this date are Lebanon from France in 1943, Iceland from Denmark in 1944, and the Japanese colonies at the end of WWII (Koreas and Taiwan). 162 colonized countries figure in the final database, out of which 152 whose separation takes place between 1939 and 1999. The end of the Russian Federation in 1991 and five more isolated returns to sovereignty (Eritrea 1993, Palau 1994, Bosnia-Herzegovina 1995, Hong-Kong 1997 and Macau 1999) are the last events before the end of the century. Figure (2) displays the number of countries that became independent over the years, with mention of their region. Immediately apparent is the high concentration of events in the early 1960s (most French colonies of Western Africa went independent in 1960). Other large spikes are the ones linked to the regime changes in Portugal in 1975, and in Russia in 1991. This offer a very wide variety of events, newly independent countries being located in all parts of the world, and recovering governance of their trade policy in quite different time periods.

\subsection{Trade data}

The trade data comes from the International Monetary Funds Direction of Trade Statistics (DOTS). It provides agregate trade flows between countries from 1948 to 2011, covering the 
Figure 2: Independent countries per year and world region

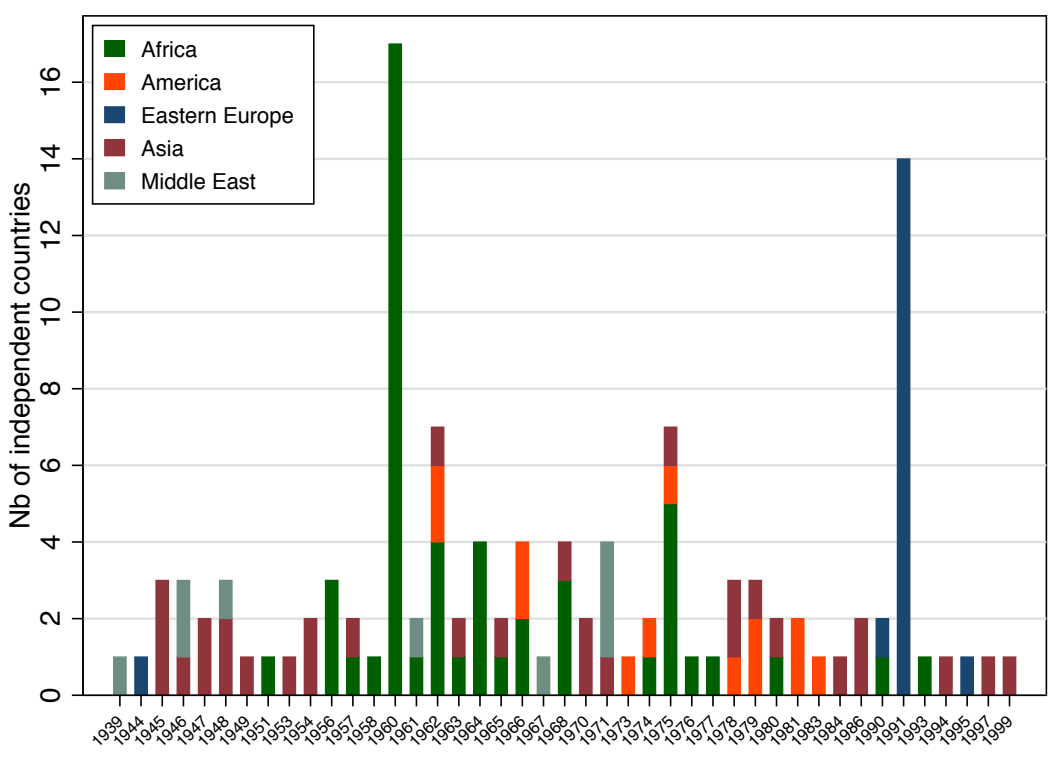

majority of the post-war separation events and also the entry of China in the WTO in 2001. The original DOTS database is compiled by Head et al. (2010) until 2006 and complemented with gravity control variables (GDPs, populations, RTAs, currency unions, and distance), as explained in Appendix A of their paper. We extend the data to the most recent years.

\section{Is there something special with China?}

This section investigates whether the main determinants of trade in the gravity equation explain the evolution of trade flows between former colonies and China. Using bilateral trade data going back to 1948, we start with a simple graphical analysis for a set of countries that became independent at the start of the period. We explore the role of production and export capacity in shaping colonies' imports from China and France. We then turn to regressions and follow Head et al. (2010) and Lavallée and Lochard (2015). We look for an effect of independence on the level of bilateral trade flows between China and former colonies, suggesting a bilateral change in the ability to trade.

\subsection{Graphical evolution of bilateral trade flows}

The graphical analysis presented in figures 1 and 3 provides a first glance at the evolution of China's trade patterns with ex-colonies. We choose several examples of former colonies and graph their trade flows both with their former colonizer and with China. The cases of these three 
ex-colonies, Algeria, Senegal and Ghana, share the advantage of having available data for most years in the sample. Algeria became independent in 1962 after several years of violent military conflict, when Senegal's sepration from the same hegemon (France) was peaceful. Ghana is an example of independence from the United Kingdom.

Let us start with the example of Algeria (first line, three top boxes). The first graph shows the evolution through time of Algerias' shares of total imports from France and from China. The share of imports from France decreases sharply, from more than 55\% in 1950 to around 20\% in 2010. The share of imports from China, instead, rises steadily, and almost catches up with the French market share at the end of the sample. The evolution is very similar for Senegal, and lines even cross for Ghana, where China is now a larger source of imports than the United Kingdom. This pattern of gradual replacement of the former colonizer by China is quite striking and calls for an investigation of its determinants.

It is useful at this stage to use the gravity equation to guide the next steps of our analysis. We refer here to the simplest version of gravity, which is the most easy to represent graphically (the theory-grounded version of gravity will be used in the next sections). The so-called "naive" gravity equation describes bilateral trade from $i$ to $n, X_{n i}$, as a function of the two countries' sizes and bilateral easiness to trade. Measuring bilateral accessibility with $0 \leq \phi_{n i} \leq 1$, and GDP with $Y$ :

$$
X_{n i}=G Y_{i} Y_{n} \phi_{n i}
$$

The graphs in the first column of figure 3 plots the import share, which, using naive gravity means

$$
\frac{X_{n i}}{\sum_{i \neq n} X_{n i}}=\frac{Y_{i} \phi_{n i}}{\sum_{i \neq n} Y_{i} \phi_{n i}}
$$

This equation highlights the straightforward dependence of this import ratio on the size of the origin country $i$ (here France and China). This is not very informative as a measure of what we want to capture, i.e. a potential change of trade costs between ex-colonies and China. A more useful measure should take into account the size of the origin country as a potential supplier. We thus divide the import share by the share of the origin country in world GDP $\left(Y_{i} / Y_{w}\right)$ :

$$
\frac{\frac{X_{n i}}{\sum_{i \neq n} X_{n i}}}{Y_{i} / Y_{w}}=\frac{\phi_{n i}}{\sum_{i \neq n}\left(Y_{i} / Y_{w}\right) \phi_{n i}} .
$$

The resulting expression, graphed in the second column of figure 3 , is proportional to the level of bilateral trade costs between the two countries, compared to the weighted average of trade costs from all other partners. When bilateral accessibility is equal to the average, the ratio of shares is equal to 1 . This normalization is represented by the horizontal lines in the second column of figure 3 .

Dividing by the exporter's share in world production brings noticeable changes to the graph. In particular, the increase in the share of imports from China is much softened compared to the 
first column, for the three countries. For Algeria and Senegal, the change is quite evident: the share of trade from China increases during the first decade after independence up to the point where trade flows are relatively close to the norm represented by a line equal to 1 . The picture is more involved for Ghana, where the change is mostly apparent at the end of the period. Accounting for the growth rates in China's GDP attenuates the spectacular increase in trade flows displayed for Ghanean imports from China shown in the first column.

At this point, according to equation (2), an upward trend in the shares of imports from China in column 2 indicates a decrease of the colony's bilateral trade costs with China, relative to its average trade cost among all trade partners. Since this is exactly what these graphs aim to capture, we investigate whether the observed trends do indicate a change in trade preferences for ex-colonies and China even when we go beyond the case of naive gravity. The developments of the gravity equation literature since Anderson and Van Wincoop (2003) emphasize the need for "multilateral resistance" (MR) terms as determinants of trade flows. These variables account for all potential supply sources for the importing country (the inward MR term), and for all possible destinations for the exporter (the outward MR term). Graphically, those can be approximated by dividing import shares by the share of the exporting country in world exports, rather than in world GDP. This is done in column 3 for Algeria, Senegal and Ghana, which displays the share of the ex-colonie's imports from the former metropole and from China, divided respectively by France's (or Great-Britain's) and China's share in world exports. The effect of dividing by countries' share in world exports is apparent for the three examples of countries. Importantly, the remaining upward trend in trade shares disappears for two out of the three countries (Algeria and Senegal), shedding doubt or a least opening the investigation about the replacement of colonizer's trade flows by imports from China.

Looking back on the different representations of trade flows between former-colonies and China, a clear pattern emerges. Adding controls for gravity determinants in the graphical representations of colonies' trade flows weakens the impression that those ex-colonies replaced the colonial power with China. The figures displayed in the third column are clearly preferable in terms of consistence with theory, and do not exhibit the catch-up pattern that was so apparent in figure 1. This also means that unilateral trade determinants such as production and export capacity are able to explain an important part of these trade flows' patterns. The need for an explanation basde on bilateral specificities is attenuated.

We now proceed to proper gravity estimations to investigate whether China's trade flows to former colonies exhibit abnormal patterns, once controlling for the outward orientation of the Chinese economy. 
Figure 3: Algeria, Senegal and Ghana's trade with colonizer and with China

\section{Trade shares}
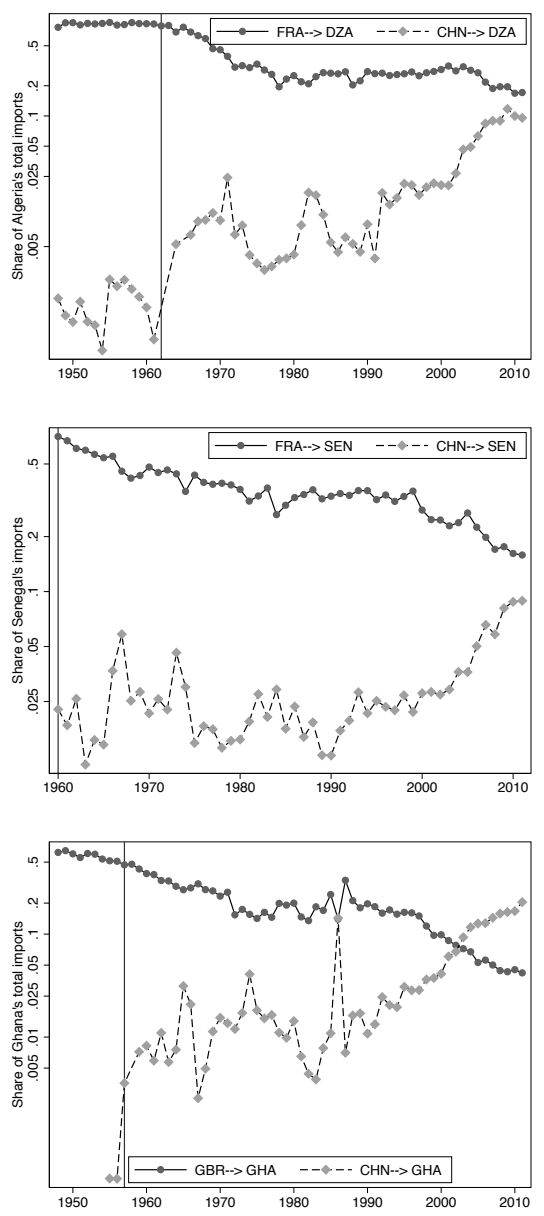

Trade shares divided by share of China in world GDP
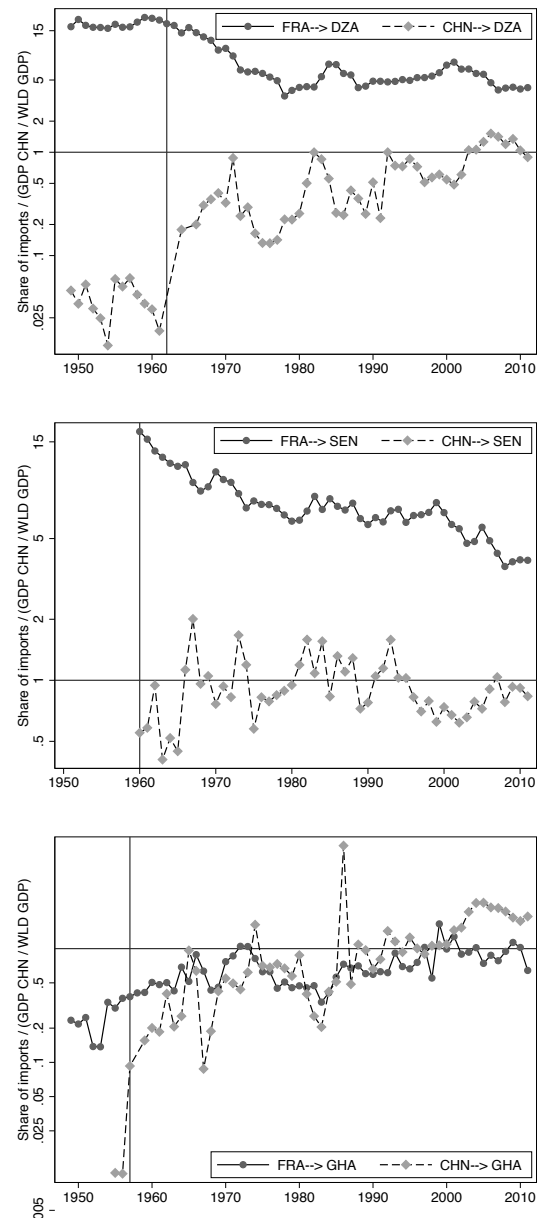

Trade shares divided

by share of China in world exports
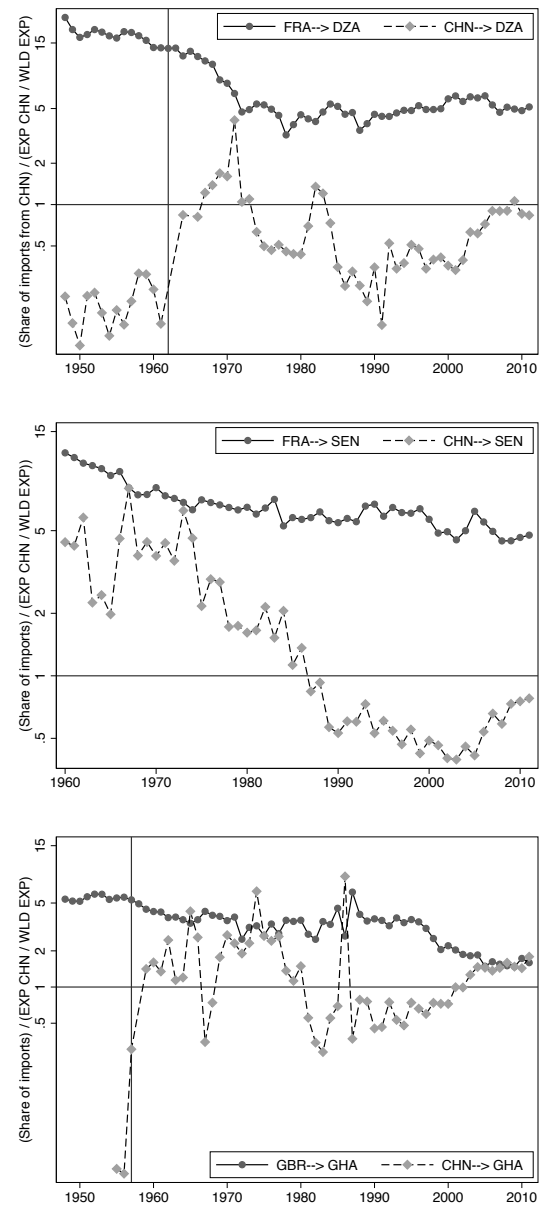

The first column contains annual import shares from France and China (line 1), Senegal (line 2) and Ghana (line 3), for Ghana and China. The second columns keeps the same countries and divides the import shares by the share of France, Ghana or China in world GDP. The last column divides the import shares by the share of France, Ghana or China in world exports. 


\subsection{Gravity estimation of post-independence trade flows with China}

Structural gravity refers to trade models in which bilateral trade determinants enter multiplicatively the trade equation and contain the following terms:

$$
X_{n i t}=\frac{Y_{i t}}{\Omega_{i t}} \frac{X_{n t}}{\Phi_{n t}} \phi_{n i t}
$$

with $Y_{i}=\sum_{n} X_{n i}$ the value of total production, $X_{n}=\sum_{i} X_{n i}$ the value of the importer's total expenditure, and $\Omega_{i t}$ and $\Phi_{n t}$ the multilateral resistance terms defined as

$$
\Phi_{n t}=\sum_{l} \frac{\phi_{n l t}}{Y} \Omega_{l t} \quad \text { and } \quad \Omega_{i t}=\sum_{l} \frac{\phi_{l i t}}{X} \Phi_{l t} .
$$

In equation (3), bilateral trade $X_{n i t}$ is a function of supply, demand, and bilateral frictions. Compared to the naive gravity equation (1), the supplier term in the structural gravity equation $S_{i t}=\frac{Y_{i t}}{\Omega_{i t}}$ weights total production $Y_{i t}$ by the exporter's multilateral resistance $\Omega_{i t}$, and the demand term $M_{n t}=\frac{X_{n t}}{\Phi_{n t}}$ weights total expenditure $X_{n}$ by the importer's multilateral resistance $\Phi_{n}$.

The almost unique application of the gravity model has been to estimate the effect of bilateral trade determinants ${ }^{6}$ Most trade models express bilateral accessibility through $0<\phi_{n i}=\tau_{n i}^{\theta}<$ 1 , in which $\theta$ is the elasticity of trade flows to trade costs, and trade $\operatorname{costs} \tau_{n i}$ contain the bilateral elements defining the level of frictions to trade between the two partners. The literature typically investigates two different types of frictions: first, those related to policy decisions, ex-post or ex-ante: the signature of regional agreements (Baier and Bergstrand (2007), Carrere (2006), Limão (2016)), GATT membership (Rose (2004), Subramanian and Wei (2007)), or currency Unions (Rose (2000), Silva and Tenreyro (2010), Glick and Rose (2002)). A second set of papers is interested in the long-run determinants of trade flows: geographical proximity (Disdier and Head (2008)), cultural proximity (Felbermayr and Toubal (2010)), through common language or institutions (Melitz and Toubal (2014), Lewer and Van den Berg (2007)). Among those, colonial history is very frequent covariate investigated, assumed to affect trade flows through common institutions and easier communications. It used to be a control variable when studying another determinant. Only quite recently has the impact of colonial linkage on trade been a topic of investigation per se (De Sousa and Lochard (2012), Mitchener and Weidenmier (2008)).

So did the effect of independence on trade, studied by (Head et al. (2010) and Lavallée and Lochard (2015). Both papers are of interest for us because they investigate not only the direct effect of independence on colonies' trade flows with the metropole, but also the direct effect of independence on colonies' trade flows with the Rest of the world: this is, whether trade preferences of former colonies have changed with given RoW partners following the break of

6 Tinbergen (1962) introduced gravity equations in economics and estimates the respective importance of British Commonwealth and Belgian trade preferences. 
colonial ties. Our analysis quantifies the three channels for trade increase described by gravity equations: our estimates of bilateral China-colonies dummies represent the second channel which can explain the surge in trade flows discussed in section (1). We thus perform similar estimations to the above-mentioned papers, however focused on China 7 .

Declining bilateral trade costs between China and former colonies are likely to make trade flows easier, and could be due to time-varying variables such as trade policy, or political relations. We can evaluate whether such a decrease happened after independence by estimating a structural gravity equation and by adding indicator variables for trade flows between China and former colonies next to the traditional elements of trade costs.

We follow standard gravity estimation procedures and take logs of equation (3), which gives:

$$
\ln X_{n i t}=\ln S_{i t}+\ln M_{n t}+\ln \phi_{n i t} .
$$

Bilateral trade costs comprise observed time-fixed and time-varying variables and unobserved bilateral trade cost determinants: $\ln \phi_{n i t}=B_{i j}+B_{i j t}+\epsilon_{n i t}$. Traditional gravity variables include geographical distance $\mathrm{D}_{i j}$, and dummies for the following situations: shared border, common language, trade agreements (RTA, GATT, ACP) and shared currency:

$$
\begin{gathered}
B_{n i}=\ln D_{n i}+\text { Border }_{n i}+\text { Lang }_{i j}+\text { ColHist }_{i j}+\text { StillCol }_{n i}+\text { ChnCol }_{n i}+\text { ChnStillCol }_{n i} \\
B_{n i t}=\text { RTA }_{n i t}+\text { GATT }_{n i t}+\text { Curr }_{n i t}+\text { ACPEU }_{n i t}+\text { IndYr }_{n i t}+\text { IndYrChn }_{n i t}
\end{gathered}
$$

The China-colonies indicator variables capture the time-varying bilateral proximity effects outside of the formal trade policy variables. Two interesting types of effects may be at work. First, recent research shows that political influence is able to affect trade flows, in particular in countries where the public administration is in charge of trade decisions. Fuchs and Klann (2013) find that the absence of political compliance affects Chinese imports: in our case one could imagine that the establishment of diplomatic relations by former colonies with the People Republic of China after its founding, could be rewarded by higher imports from China in the subsequent years. On the same mechanism but on other countries, Berger et al. (2013) identify that increased US political influence measured by CIA interventions had large positive effects on US exports to these countries. In a less tense context, Nitsch (2007) shows that state and official visits from US, German and French representatives have a trade-increasing effect.

The second possible effect that might be captured by the China-colonies dummies relates to informal networks. The literature emphasizes that international business networks are very powerful at influencing trade flows (Chaney (2014) for the theoretical analysis). Changes in

\footnotetext{
${ }^{7}$ Note that estimating bilateral China-colonies dummies cannot be used to quantify the redirection of trade flows following independence, in contrast with the analysis of (Head et al. (2010) and Lavallée and Lochard (2015). Computing the redirection effect requires to obtain the counterfactual trade flows incorporating the changes in trade cost and in multilateral resistances. This is what we do in section 4.
} 
informal proximity between partners might influence the tightening of commercial relations between China and former colonies (Rauch (2001), Berthou and Ehrhart (2014) among others).

Our interest lies in the evolution of trade flows between former colonies and China in the years subsequent to their independence. We now explain how we allow the effect to vary year by year. Following Head et al. (2010), we measure the existence of a colony-China trade specificity with dummy variables that each correspond to a given number of years since the independence of the former colony, IndYr1Chn $\mathrm{Cit}_{\text {it }}$ to IndYr65Chn $\mathrm{Chit}_{\text {. }}$

The benchmark to which each year dummy is compared is the average trade level between colonies and China during colonial time, captured by the dummy variable $\mathrm{ChnCol}_{n i}$. It is set to one for all trade flows between colonized countries and China, in both directions. Trade of pairs of countries outside of our interest group are controled for by suitable variables: $\mathrm{ChnStillCol}_{n i}$ controls for trade flows between China and ongoing colonies such as Guadeloupe (FR), Aruba (NL) or Falkland Islands (GBR). Dyadic variables include the independence variables used in Head et al. (2010) so as to take into account the decreasing effect of separation on bilateral trade between colonies and metropoles. The IndYr1 $1_{n i t}$ to IndYr65 $5_{n i t}$ bilateral dummies measure the number of years since independence, for all colonies in the sample, and are defined for flows between former colonies and their former colonial power. Parallel to the Chinese dummies, the benchmark trade level during colonial time for the pair is given by a country-pair variable, ColHist $_{n i}$, which turns on for pairs ever in a colonial relationship. StillCol ${ }_{n i}$ sets on for ongoing colonial relationships at the end of the database (2011). Yearly independance dummies for former colonies thus compute the effect of time with respect to the level during colonial time.

\subsection{Estimation issues}

The concern about controlling for supply and demand characteristics, highlighted in the graphical illustration of trade flows, is naturally also part of the gravity estimation strategy. Estimating trade effects of bilateral determinants requires to account for the time-varying supply, demand, and alternative destinations or sources of supply (MR terms). Following common practice in theory-consistent gravity estimation, we control for these variables by using country-time fixed effects $F_{i t}$ and $F_{n t}$ which capture the monadic terms $\ln S_{i t}$ and $\ln \mathrm{M}_{n t}$. The unilateral timevarying determinants of trade, population and GDP per capita, drop in specifications using country-time fixed-effects.

We add country pair dummies $\mathrm{F}_{n i}$ to our preferred specification, in order to control for potentially omitted bilateral variables that might correlate with the consequences of independence and are constant through time (long-run historical relationships, etc.). The China-colonies indicator variables are therefore identified through their change over time. With those country-time fixed-effects and dyadic dummies, our estimated equation writes:

$$
\ln X_{n i t}=a+F_{i t}+F_{n t}+F_{n i}+\mathbf{b} B_{n i t}+\epsilon_{n i t},
$$


where $\epsilon_{\text {nit }}$ captures the unobserved factors that influence bilateral trade between the country pair, in addition to the vector of observed trade costs $B_{n i t}$ and to the set of fixed-effects. Our estimations identify China-former colonies specificities in the time-dimension: the timing of independence was "decided" between the hegemon and the colonized country, which makes its exogeneity a quite reasonable assumption 8

The second methodological point consists in dealing with zero trade flows. It has become standard practice to keep the zeroes in bilateral trade regressions through the use of PPML. This econometric estimator was promoted by Silva and Tenreyro (2006) to account for heteroskedasticity. Its use of the level of trade flow (rather than log of trade flows) as a left-hand side variable also permits to keep the zeroes in regressions. We report estimates of equation (8) with the Poisson PMLE to check for robustness to this specification. Computational constraints impede the simultaneous use of dyadic and country-year fixed-effects, we therefore present regressions with Poisson and dyadic dummies in parralel to the OLS specification with the same controls.

Last, we investigate the determinants of former colonies initiating to trade with China during the post-independence period. We investigate whether more years of independence impact significantly the probability to have positive trade flows within these country pairs. We therefore estimate the specification with a Linear Probability Model (LPM) with the dependent variable being a binary indicator for positive flows.

\subsection{Gravity controls results}

We estimate a gravity equation on trade flows from all countries, between 1948 and 2011. Results for the unilateral and bilateral control variables figure in Table 1, and partial trade effects for China-former colonies pairs are graphed in figure 4 , in six panels which correspond to the six specifications used.

Monadic determinants are captured by population and GDP per capita in the benchmark specification in column 1, which uses OLS and time dummies and thus illustrates the original atheoretical gravity equation estimation. Fixed-effects are introduced sequentially in columns 2 (dyadic) and 4 (country-time), and used together in column 5. Unilateral variables as well as time-fixed bilateral determinants are captured by these fixed-effects in column 5, which displays effects estimated on the remaining time-variation of bilateral variables for a given country pair. Standard errors in each column are clustered by dyad. Robustness checks using Poisson estimator with dyadic fixed-effects figure in column 3, and thus differ from column 2 only by the addition of zero flows. Finally, results from the linear probability model with both sets of fixed-effets on positive flows are shown in the last column.

The first specification shows that increases in GDP per capita and in population affect

\footnotetext{
${ }^{8}$ China was a very small actor in international trade in the 1950 s and 1960s when most independence events took place, which makes it very unlikely that ex-colonies decided to separate from their metropole because of expected higher trade with China
} 
Table 1: Gravity regressions control variables

\begin{tabular}{|c|c|c|c|c|c|c|}
\hline \multirow{3}{*}{$\begin{array}{l}\text { Dep. var. } \\
\text { Method }\end{array}$} & (1) & $(2)$ & \multirow{3}{*}{$\begin{array}{c}(3) \\
\text { flow } \\
\text { PPML }\end{array}$} & (4) & (5) & \multirow{3}{*}{$\begin{array}{c}(6) \\
0 / 1 \\
\text { OLS }\end{array}$} \\
\hline & \multicolumn{2}{|c|}{$\ln ($ flow $)$} & & \multicolumn{2}{|c|}{$\ln ($ flow $)$} & \\
\hline & OLS & OLS & & OLS & OLS & \\
\hline \multirow[t]{2}{*}{$\ln \operatorname{Pop}_{i t}$} & $1.013^{a}$ & $0.356^{a}$ & $0.525^{a}$ & & & \\
\hline & $(0.006)$ & $(0.041)$ & $(0.080)$ & & & \\
\hline \multirow[t]{2}{*}{$\ln \operatorname{Pop}_{n t}$} & $0.845^{a}$ & $1.002^{a}$ & $0.539^{a}$ & & & \\
\hline & $(0.006)$ & $(0.037)$ & $(0.071)$ & & & \\
\hline \multirow[t]{2}{*}{$\ln (\mathrm{GDP} / \mathrm{Pop})_{i t}$} & $1.145^{a}$ & $0.743^{a}$ & $0.764^{a}$ & & & \\
\hline & $(0.007)$ & $(0.015)$ & $(0.023)$ & & & \\
\hline \multirow{2}{*}{$\ln (\mathrm{GDP} / \mathrm{Pop})_{n t}$} & $0.909^{a}$ & $0.646^{a}$ & $0.676^{a}$ & & & \\
\hline & $(0.007)$ & $(0.014)$ & $(0.024)$ & & & \\
\hline \multirow[t]{2}{*}{$\ln$ Dist $_{n i}$} & $-1.033^{a}$ & & & $-1.323^{a}$ & & \\
\hline & $(0.015)$ & & & $(0.015)$ & & \\
\hline \multirow[t]{2}{*}{ Shared Border $_{n i}$} & $0.652^{a}$ & & & $0.459^{a}$ & & \\
\hline & $(0.071)$ & & & $(0.072)$ & & \\
\hline \multirow{2}{*}{ Language $_{n i}$} & $0.671^{a}$ & & & $0.559^{a}$ & & \\
\hline & $(0.031)$ & & & $(0.029)$ & & \\
\hline \multirow{2}{*}{ Colonial History $_{n i}$} & $2.226^{a}$ & & & $2.009^{a}$ & & \\
\hline & $(0.241)$ & & & $(0.149)$ & & \\
\hline \multirow[t]{2}{*}{ Still Colony $2011_{n i}$} & $-1.197^{c}$ & & & -0.372 & & \\
\hline & $(0.632)$ & & & $(0.339)$ & & \\
\hline \multirow[t]{2}{*}{ China - $\mathrm{Col}_{n i}$} & $0.627^{c}$ & & & -0.141 & & \\
\hline & $(0.329)$ & & & $(0.326)$ & & \\
\hline \multirow[t]{2}{*}{ China - Still colony $n i$} & $-1.407^{a}$ & & & $-1.115^{a}$ & & \\
\hline & $(0.496)$ & & & $(0.376)$ & & \\
\hline \multirow{2}{*}{$\mathrm{FTA}_{n i t}$} & $0.854^{a}$ & $0.384^{a}$ & $0.240^{a}$ & $0.604^{a}$ & $0.428^{a}$ & $-0.066^{a}$ \\
\hline & $(0.037)$ & $(0.023)$ & $(0.038)$ & $(0.036)$ & $(0.025)$ & $(0.005)$ \\
\hline \multirow[t]{2}{*}{ Both $\mathrm{GATT}_{n i t}$} & $0.193^{a}$ & $0.210^{a}$ & $0.340^{a}$ & $0.380^{a}$ & $0.175^{a}$ & $0.020^{a}$ \\
\hline & $(0.019)$ & $(0.016)$ & $(0.037)$ & $(0.036)$ & $(0.029)$ & $(0.004)$ \\
\hline \multirow[t]{2}{*}{ Shared Currency $_{n i t}$} & $0.733^{a}$ & $0.423^{a}$ & $0.126^{a}$ & $0.810^{a}$ & $0.311^{a}$ & $0.018^{c}$ \\
\hline & $(0.086)$ & $(0.059)$ & $(0.032)$ & $(0.075)$ & $(0.052)$ & $(0.009)$ \\
\hline \multirow[t]{2}{*}{$\mathrm{ACP}$ to $\mathrm{EU}_{n i t}$} & $0.156^{a}$ & $-0.680^{a}$ & $-0.200^{b}$ & $0.376^{a}$ & -0.036 & $0.112^{a}$ \\
\hline & $(0.059)$ & $(0.053)$ & $(0.100)$ & $(0.054)$ & $(0.051)$ & $(0.008)$ \\
\hline Observations & 731622 & 731622 & 1073038 & 818071 & 818071 & 1358554 \\
\hline$R^{2}$ & 0.621 & 0.834 & & 0.713 & 0.853 & 0.647 \\
\hline Country-time fixed-effects & - & - & - & yes & yes & yes \\
\hline Country-pair fixed-effects & - & yes & yes & - & yes & yes \\
\hline Time dummies & yes & yes & yes & yes & yes & yes \\
\hline
\end{tabular}


positively trade flows both for the importer and the exporter with coefficients close to unity. The trade elasticities with respect to the destination variables are both lower than those of the origin country, in line with Feenstra et al. (2001)'s predictions. The elasticity of trade to distance (-1.033) is close to the average value (-0.9) reported by Disdier and Head (2008) and to the average elasticity of -0.93 obtained in Head and Mayer (2014) on the same sample updated after 2005. Comparing the distance coefficient in columns 1 and 4 shows that it is biased towards zero when estimated without country-year fixed-effects, which follows the results by Baldwin and Taglioni (2007). Other time-invariant geographical determinants include contuiguity and a shared language. The average effect of the border dummy is reported to be between 0.53 and 0.66 by Head and Mayer (2014) according to the specification used. The language indicator has similar average estimates (0.54 and 0.39$)$. Our results confirm a very comparable impact: 0.652 and 0.671 respectively for the border and language using naive gravity, 0.459 and 0.559 when controlling for country-time effects.

The ex-post effect of participating in a free trade agreement is positive on country pairs' trade flows, with a coefficient of 0.854 using basic gravity. This is larger than the average effect of 0.59 reported in the meta-analysis by Cipollina and Salvatici (2010). We also include a dummy for the pairwise participation in the GATT negociations: its impact is positive using naive or structural gravity, and so is the estimate of the EU ACP programme directed at developing countries in the Caribean and Pacific region.

The time-invariant China-colony dummy sets the benchmark to which the yearly Chinacolony effects are compared to. It turns on for all flows between China and colonies. Since post-independence trade between China and a former colony is captured by the annual dummies following the break-up, $\mathrm{ChnCol}_{n i}$ measures the trade level before separation up to the first year of independence. Its coefficient appears unstable as it switches sign between columns (1) and (4), and is non-significant in the latter, suggesting that former colonies' trade flows with China are not significantly different from their trade relations with other partners, besides the metropole, before independence.

$\mathrm{ChnStillCol}_{n i}$ adds to $\mathrm{ChnCol}_{n i}$ to measure trade flows between China and ongoing colonies throughout the period. Its negative and significant coefficient both in the naive (-1.407) and the structural estimation (-1.115) indicates that in average, trade flows between colonized countries and China are less-than-proportional to what they could be, given the size of partners and their bilateral trade costs. This results will be echoed by our experiment in the next section, investigating predicted trade flows under the counterfactual absence of independence. The intuition builds on the trade-creating effect of colonial history for metropoles and colonies (De Sousa and Lochard (2012)). Our coefficient on the China-ongoing colonies pairs indicates that trade between ongoing colonies and third countries (such as China) could be higher if colonies were independent: the redirection effect implies that price indices of both countries absorb the change in the trade cost of the colony-metropole and generate increased trade flows with ROW. 
The remaining columns in table 1 provide robustness estimations with different estimators and samples. Results estimated with PPML have the same sign as those estimated with OLS, and exhibit patterns emphasized in Head and Mayer (2014): the effects of countries' size tend to be smaller in absolute value, PPML giving more weight to large flows in levels. Last, column (6) investigates whether the same determinants as above explain whether two countries have zero or positive trade flows. The dummy for positive flows is the explained variable, and the linear probability model is used on the time-varying dyadic determinants, with the full set of fixed-effects.

\subsection{China-colony partial effects}

Figure 4 shows the estimates of the yearly effects of Chinese relations with former colonies after their independence. The six panels correspond to the specifications used in Table 1. Each black diamond is the exponential of the estimated China-colony effect for a given number of years after independence. The grey-shaded area represents the $90 \%$ confidence interval. Exponentiated independence effects estimated in Head et al. (2010) are displayed with shaded bullets in the same panels as a check and comparison.

Estimates shown in the first panel depict an evolution which fits closely with the extraordinary role imputed to China in former colonies's trade. Trade for these pairs of countries rises above the pre-independence level during the first decade after independence, and increases steadily until fifty years following separation. According to these results based on time dummies, Chinese trade flows to ex-colonies could be interpreted as displaying abnormally high levels, suggesting an unobserved policy change or informal strenghtened bilateral relations following independence. With only time dummies in the estimation, note that it is impossible to know whether the higher trade between China and former colonies derives from the decrease of their bilateral trade costs or from the indirect impact of independence from the metropole, channeled through the price indices. More, since dyadic fixed-effects are not included, we cannot interpret the effect as working only through the time-dimension. We proceed to the necessary inclusion of control variables and theory-consistent determinants in the next boxes.

Second panel estimates answer one of these caveats by adding dyadic dummies, which restrict the identification to time-variation within China-former colonies trade flows. Since this specification controls for time-invariant variables, the persistent impressive increasing trend shown by the black diamonds could be interpreted as a confirmation of the first panel's singular role of China. For such a conclusion to hold, the remaining checks for rigorous estimation include taking account of zero trade flows, and using together the full set of fixed-effects. Column 3 estimates the same specification on the sample including zero flows, and results are displayed in the third panel of figure 4. Estimates are obtained from the Poisson PMLE and using dyadic fixed-effects. Here again, the outcome prevails in showing China-colonies effects on trade that are increasing in time. 
Further panels however prevent from developing the story, and shed light on the different results obtained when taking into account the size of countries (among which China), hence their production and export capacity. Country-time fixed-effects are added to OLS in panel 4, and used together with dyadic fixed effects in panel 5. While estimates show excess trade flows for a sub-period of the sample, in both panels trade erodes (suddenly in panel 4, steadily in panel 5) to around 40 to $50 \%$ of the expected level. Results obtained with both sets of fixedeffects are theory-consistent and allow a straightforward interpretation: taking into account the export and import capacities of countries, trade flows between former colonies and China after independence are not different from their level during the colonial period. Said differently, trade flows are not more than proportional to the level that could be expected each year, given the sizes and accessibilities of countries. In specification 5, which we favor because it includes theorygrounded controls for size and dyadic time-fixed determinants, former colonies' trade flows with China display a decreasing time-trend after their separation from the metropole, which is however rarely significant. One might think that our results are overly pessimistic since part of the China-colonies effect might be captured by other variables in the regression. However, no colonized country installed Chinese as a common language, and no colonized country has signed a free trade agreement with China before 2004. China signed preferential trade agreements at the very end of our sample: the China-ASEAN FTA was implemented in 2010. The only earlier FTA signed by China with a former colony that we consider is with Pakistan and entered into force in 2008.

While these results relate to the intensive margin of trade, let us last investigate whether any China-colony specificity can be identified on the likelyhood to develop new trade relationship within the pair. The last panel displays the effect of years of independence on the probability that former colonies build new trade relations with China after independence. We code the positive flows as one and estimate the specification using OLS with dyadic dummies and country-time fixed-effects. Results from the linear probability model exhibit a similar decreasing time-trend to the one obtained on the intensive margin, only shifted upwards. The higher probability to trade with China erodes after thirty years of independence and becomes mostly non significant. The dyadic fixed-effects focus the interpretation on whithin time variation: the increased probability to trade is compared to the likelihood of positive flows during the colonial period.

It is useful at this stage to summarize our investigation of the different channels that may explain the surge in trade flows between China and ex-colonies. In this section we have shown that China-colonies dummies, standing for specific bilateral trade relations, are not significant reasons to explain the trade patterns between these pairs of countries. Estimating a structural gravity equation confirms the naive graphical representations of trade flows, in which the inclusion of the basic determinants of trade is able to suppress, or at least strongly attenuate, the upward trend in ex-colonies' share of imports from China. According to our results, so far we have shown that trade flows between former colonies and China do not rely on bilateral changes 
in trade preferences. On the contrary, the unilateral variables production and export capacity do account for important determinants of trade flows.

We now turn to the third channel through which a structural gravity equation can explain a surge in post-independence Chinese trade flows to former colonies.

\section{The gravity equation, trade costs and the redirection effect}

Although China is thought of having developed intense trade relations in particular with formerly colonized countries, gravity estimations on trade flows during 1948-2011 do not highlight significant coefficients on post-independence trade flows for these pairs.

This finding does not however rule out that former colonies' level of trade with China is influenced by their colonial past. Indeed, structural gravity equations state that a trade cost change does not only generate a Partial Trade Impact (mesured by exponentiating the estimated coefficient), but is also followed by indirect trade increases for all other pairs, through the adjustment of multilateral resistances $\Omega_{i t}$ and $\Phi_{n t}$. Head and Mayer (2014) label this effect the Modular Trade Impact (MTI), which measures the indirect effect of a trade cost change on thirdcountries' trade flows, holding GDPs constant? In the case of independence, structural gravity implies that the trade cost increase between former colonial pairs generates a redirection of trade flows (the MTI) towards all other countries in the world. The redirection channels through price indices of all countries, which vary following the change in independence trade costs. We may thus expect that trade between former-colonies and China has risen following independence events, due to the reorientation of trade flows.

Measuring the indirect effect of independence cannot be achieved by estimation since it requires to compute a counterfactual situation. We thus quantify the share of trade flows increase between China and former colonies that is due to the division of colonial empires, by using the so-called two-step MTI procedure. We first compute the predicted trade level between China and former colonies, given GDPs and factual bilateral trade costs. We need to compute this 'theoretical trade' matrix mimicking real trade flows, in order to compare it to the second, alternative trade matrix. The second step is thus to calculate counterfactual trade levels that would have occured if trade costs hadn't involved independence of former colonies from their metropole. The only difference between the two predicted trade levels is thus the historical separation of colonized countries from their hegemon.

\footnotetext{
${ }^{9}$ Note that the General Equilibrium Trade Impact - GETI - could also be computed. It assesses the trade creation effect, trade diversion, and induced changes in incomes. We concentrate on quantifying the redistribution effect on trade that is caused by independence. GETI would go further and recalculate the GDPs' adjustments, including more than just the the reallocation of trade effect.
} 
Figure 4: Partial Trade effects of China-former colonies bilateral accessibility
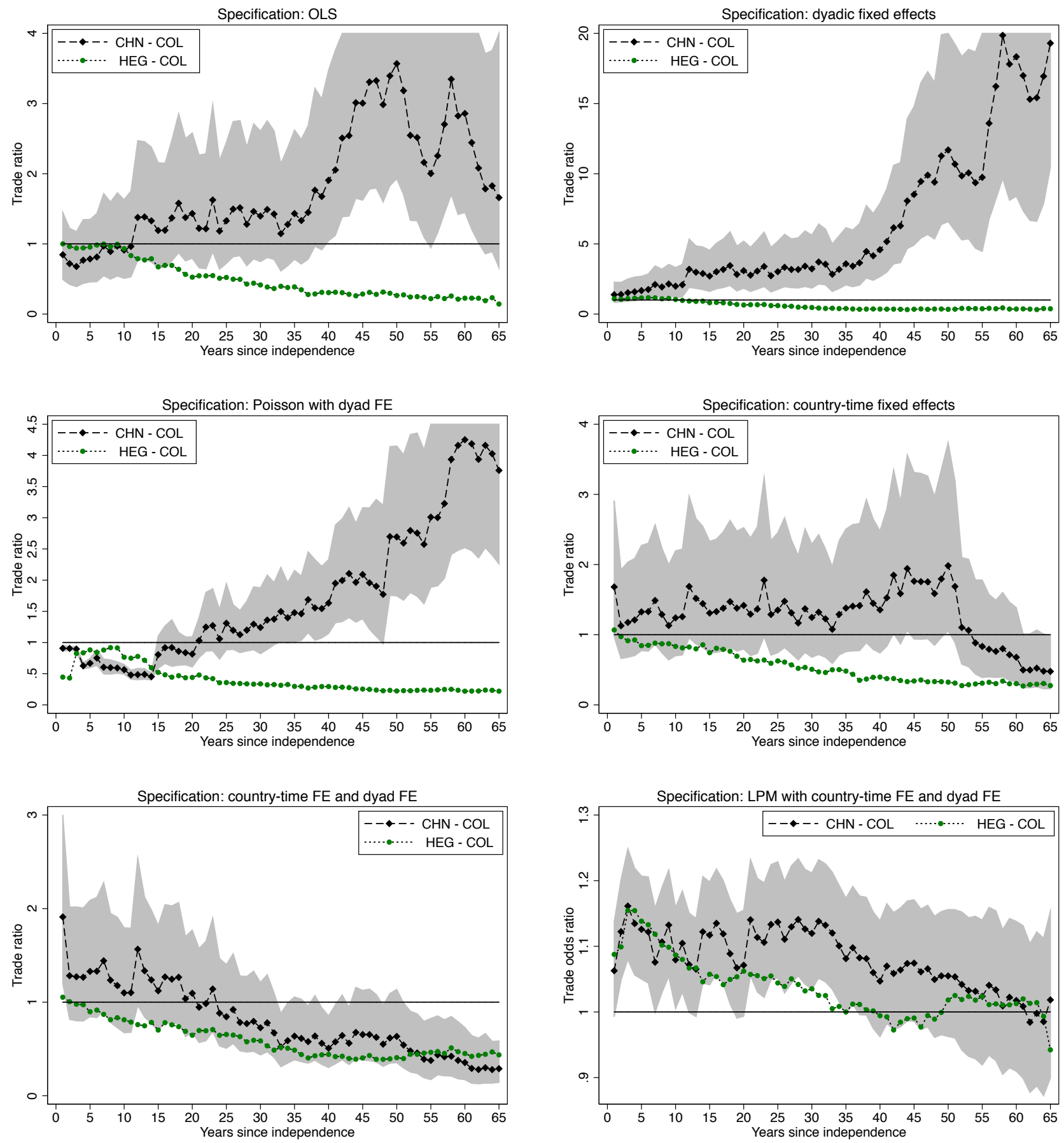


\subsection{Partial effects}

The first step involves computing predicted trade. Let us assume that bilateral trade costs contain the same time-varying determinants as in equation (7), only the China-colony bilateral effects are omitted because the counterfactual focuses on the effect of independence from the metropole:

$$
B_{n i t}=\mathrm{RTA}_{n i t}+\mathrm{GATT}_{n i t}+\mathrm{Curr}_{n i t}+\mathrm{ACPEU}_{n i t}+\mathrm{IndYr}_{n i t}
$$

We use the previously estimated coefficients to reconstruct $\ln \phi_{n i}$ for each pair of countries. Note that because bilateral accessibility contains both time-invariant and time-varying determinants, all coefficients aren't available in our preferred specification, which captures time-fixed bilateral variables through country-pair dummies (column 5 in Table 1). We thus borrow the estimated coefficients from two different specifications. Coefficients for time-invariant variables (distance, contiguity, language, and invariant colonial history) are issued from the OLS estimation of the gravity equation (column 1 in Table 1), to which time dummies and dyadic clusters are added. Coefficients for time-varying variables (trade agreements, currency unions, and colonial history) are taken from the gravity estimation with country-time fixed-effects and dyadic dummies. The bilateral trade cost $\phi_{n i}$ is assembled by exponentiating the sum of products between estimated coefficients (partial effects) and factual trade cost variables.

Using $\phi_{n i}$ together with factual $Y_{i}$ and $X_{n}$, a contraction mapping ${ }^{10}$ based on equation (4) gives $\Phi_{n}$ and $\Omega_{i}$. Trade costs, GDPs and computed multilateral resistances are then plugged into equation (3) to obtain predicted factual trade $X_{n i t}$. Despite the minimal number of variables and the imposed structure, the "fake" trade obtained through the structural gravity equation correlates at $73 \%$ with real trade.

We are now able to build the counterfactual story by changing one element of bilateral trade costs. Note that the MTI procedure is able to simulate different scenarios for all variables that are part of bilateral accessibility. The literature contains various examples of counterfactual computations using MTI. Glick and Taylor (2010) estimate the cost of military conflicts in terms of lost trade. Anderson and Yotov (2010) simulate the impact of an agreement on Canadian provinces' internal trade. In the following, we simulate the continuity of colonies and focus on its impact on trade with third countries.

\subsection{Counterfactual trade and the ratio of new to original trade}

$\phi_{n i}$ is the variable through which we simulate the alternative scenario. By turning off one of the components, we obtain the new freeness of trade index $\phi_{n i}^{\prime}$. We wish to cancel the increases in trade costs between colonies and metropoles following independence, hence to cancel the separation of colonial empires. We choose to do so for all countries whose independence date is

\footnotetext{
${ }^{10}$ We use the Stata contraction mapping ado file made available by Head and Mayer (2014) on their gravity websit https://sites.google.com/site/hiegravity/stata-programs
} 
later than 1883. Countries that separated before 1883 are thus considered as independent. All colonial relations that were ongoing in 1883 are coded as continuying in the counterfactual.

The new bilateral accessibility $\phi_{n i}^{\prime}$, combined with $Y_{i}$ and $X_{n}$, is plugged again into the contraction mapping calculation to obtain the counterfactual $\Omega_{i}^{\prime}$ and $\Phi_{n}^{\prime}$, and then counterfactual trade $X_{n i}^{\prime}$. Note that because the effect runs through an adjustment of multilateral resistances, all country pairs trade flows are affected by the change in trade costs caused by inversing the independence events. We thus compute the world matrix of trade that would have prevailed in the absence of independence events. For any country pair, the comparison between the baseline trade and the counterfactual trade can be obtained. Following Head and Mayer (2014), for any change in trade cost the ratio of new bilateral trade to original trade, taking multilateral changes into account, is given by:

$$
M T I_{n i}=\frac{X_{n i}^{\prime}}{X_{n i}}=\exp \left[\beta\left(B_{n i}^{\prime}-B_{n i}\right)\right] \times \frac{\Omega_{i}}{\Omega_{i}^{\prime}} \frac{\Phi_{n}}{\Phi_{n}^{\prime}}
$$

The intuition for the effect on Chinese trade flows, particularly since the division of colonial empires, is the following. With independence, trade costs increase between colonies and their former metropole. Although historical and institutional proximity may remain tight, separation creates new barriers to the movement of goods, but also to the exchange of information, to the flows of capital, services, and people. The gravity model for trade in goods predicts that higher trade costs impact not only trade between former colonized countries and their head of empire, but also the rest of world trade flows. Former colonies trade with third countries, and even trade between pairs of third-countries, increase, however in different proportions. The increase is due to price indexes absorbing the trade cost change and thus modifying upwards the denominator of the structural gravity equation. All imports other than from the hegemon will increase, including the ones from China.

\subsection{Results}

Part of the increase in trade flows between China and former colonies would not have been observed under the counterfactual of persistent colonial relationships. We thus expect lower predicted trade flows associated to the absence of independence events, and thus a ratio of new to original trade below one. Table 2 displays the ratios of predicted imports from China without independence over predicted imports from China with independence, for former colonies of either France, Great-Britain, or Russia. The ratio is computed in levels for each year shown in the table. The table indicates for example, that in 1970 trade flows between China and French colonies would have been $7 \%$ lower, had independence not happened. Said differently, the contribution of independence to bilateral trade flows of former colonies with China is an increase by $7 \%$ for the year 1970 .

The same comparisons are made for British, and Russian former colonies, the latter number 
Table 2: Predicted ratio of imports from China, without independence

\begin{tabular}{lccc}
\hline Year & France & Great-britain & Russia \\
\hline 1970 & .93 & .99 & \\
1975 & .89 & .98 & \\
1980 & .89 & .98 & \\
1985 & .9 & .97 & \\
1990 & .86 & .97 & \\
1995 & .83 & .96 & 1 \\
2000 & .84 & .94 & .94 \\
2005 & .83 & .93 & .9 \\
2010 & .85 & .93 & .84 \\
\hline Columns contain the ratio of average predicted \\
imports from China without independence, over \\
average predicted imports with independence (for \\
each group of former French, British, or Russian \\
colonies). Predicted exports are computed ac- \\
cording to the modular trade impact method fol- \\
lowing Head and Mayer (2014).
\end{tabular}

available after independence of its colonies in 1991. All three groups report below one numbers, indicating a positive effect of independence on outside-pairs trade. The ratio of counterfactual over predicted trade decreases: this pattern comes from the estimated independence effect, which gets larger as time passes since independence. It also highlights that the contribution of separations to the redistribution of trade is larger in recent years. In 2010 trade flows between China and former colonies are $15 \%$ higher than what they would have been with the persistence of colonial relationships.

These differences in trade flows by year are presented graphically in figure (5). The two panels display the evolution of the model-predicted shares of imports from China, computed alternatively with factual trade costs and with counterfactual trade costs that cancel independence events. In echo to the previous results, we observe an increasing effect of independence on trade flows with China, for Algeria, Senegal and Ghana.

Last, table 3 displays the difference in amount of change of trade since 1995. One reads for instance, that if they were still under colonial domination, between 1995 and 2010 the growth of French colonies imports from China would have been 15\% lower. On average, trade flows have increased by $15 \%$ more than what they would have done under persistent colonial relationships. At this point it is useful to recall our initial question in this paper, which investigates the main explanations fot the surge in Chinese trade with former colonies since independence. The outcome quantifies the third channel contained in structural gravity equations, which requires to compute counterfactual trade since it operates through the multilateral indices. Results show that the indirect effect is effective in explaining a substantial part of the trade increase with China. 
Figure 5: Differences in trade flows with and without independence
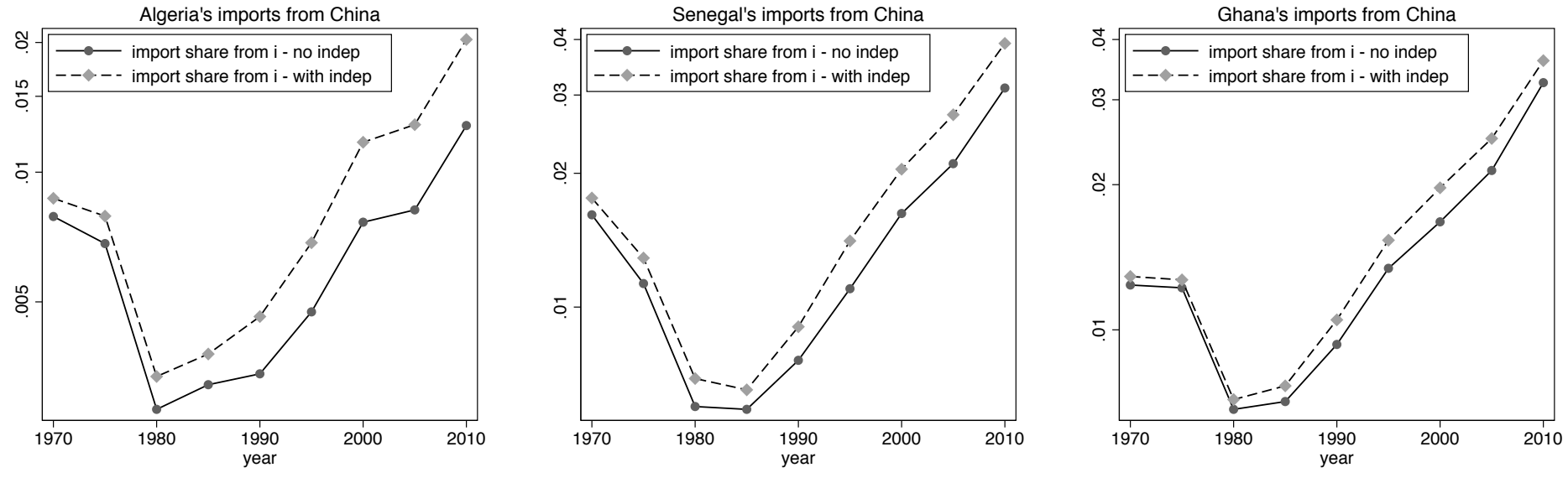

Table 3: Predicted growth in imports from China since 1995, without independence

\begin{tabular}{cccc}
\hline Year & France & Great-britain & Russia \\
\hline 2000 & .88 & 1.04 & .83 \\
2005 & .84 & .91 & .85 \\
2010 & .85 & .93 & .82
\end{tabular}

Columns contain the ratio of the average change in predicted exports from China since 1995 for the group of former French, British, Russian colonies. Predicted exports are computed according to the modular trade impact method following Head and Mayer (2014). 


\section{Conclusion}

In this paper we investigate the often heard idea that China has taken over an exceptional trade role in former colonies, replacing the former hegemon in the hierarchy of preferential market access. Indeed imports of those countries from China have risen markedly over time, to currently reach similar levels to what the countries import from the former colonizer.

We show that this pattern can be fully explained by the typical trade determinants of the theory-consistent gravity literature. In other words, contrary to what ex-colonial countries still import from their former metropole, we don't find an abnormaly high flow when the exporter is China.

Our paper can be viewed as a illustration of two important facts. First, the structural version of gravity is a very useful tool to disentangle the effects of bilateral versus multilateral frictions on trade. In our case, the impressive increase of China's exports to the colonial world is entirely explained by the multilateral part. On the importer side, the multilateral resistance effect is the 'normal' reallocation effect of trade towards countries other than the ex-hegemon (including China). On the outward side, the gravity equation takes into account that China has become a more performant exporter (towards all countries in the world) during this period. Nothing special is left to be explained by a change in the bilateral frictions between ex-colonies and China. Second, our results might also illustrate the importance of formal trade integration. Lacking linguistic, historical and cultural linkages with most of the colonial countries, China thus benefitted from the redirection following independence like any other country. Note that China did not sign over that period formal preferential agreements that might have triggered a higher share of trade by newly independent countries. The recent change in the Chinese

attitude towards preferential trade agreements offers on this ground interesting perspective of future research. 
Table 4: List of colonies in our sample

\begin{tabular}{|c|c|c|c|c|c|}
\hline Year & Colony & Metropole & Year & Colony & Metropole \\
\hline 1943 & Lebanon & France & 1966 & Guyana & United Kingdom \\
\hline 1944 & Iceland & Denmark & 1966 & Lesotho & United Kingdom \\
\hline 1945 & North Korea & Japan & 1967 & Yemen & United Kingdom \\
\hline 1945 & South Korea & Japan & 1968 & Equatorial Guinea & Spain \\
\hline 1945 & Taiwan & Japan & 1968 & Mauritius & United Kingdom \\
\hline 1946 & Jordan & United Kingdom & 1968 & Nauru & Australia \\
\hline 1946 & Philippines & United States of America & 1968 & Swaziland & United Kingdom \\
\hline 1946 & Syrian Arab Republic & France & 1970 & Fiji & United Kingdom \\
\hline 1947 & India & United Kingdom & 1970 & Tonga & United Kingdom \\
\hline 1947 & Pakistan & United Kingdom & 1971 & Bahrain & United Kingdom \\
\hline 1948 & Burma & United Kingdom & 1971 & Bangladesh & Pakistan \\
\hline 1948 & Israel & United Kingdom & 1971 & Qatar & United Kingdom \\
\hline 1948 & Sri Lanka & United Kingdom & 1971 & United Arab Emirates & United Kingdom \\
\hline 1949 & Indonesia & Netherlands & 1973 & Bahamas & United Kingdom \\
\hline 1951 & Libya & Italy & 1974 & Grenada & United Kingdom \\
\hline 1953 & Cambodia & France & 1974 & Guinea-Bissau & Portugal \\
\hline 1954 & Laos (Democratic Republic) & France & 1975 & Angola & Portugal \\
\hline 1954 & Viet Nam & France & 1975 & Cape Verde & Portugal \\
\hline 1956 & Morocco & France & 1975 & Comoros & France \\
\hline 1956 & Sudan & United Kingdom & 1975 & Mozambique & Portugal \\
\hline 1956 & Tunisia & France & 1975 & Papua New Guinea & Australia \\
\hline 1957 & Ghana & United Kingdom & 1975 & Sao Tome and Principe & Portugal \\
\hline 1957 & Malaysia & United Kingdom & 1975 & Suriname & Netherlands \\
\hline 1958 & Guinea & France & 1976 & Seychelles & United Kingdom \\
\hline 1960 & Benin & France & 1977 & Djibouti & France \\
\hline 1960 & Burkina Faso & France & 1978 & Dominica & United Kingdom \\
\hline 1960 & Cameroon & France & 1978 & Solomon Islands & United Kingdom \\
\hline 1960 & Central African Republic & France & 1978 & Tuvalu & United Kingdom \\
\hline 1960 & Chad & France & 1979 & Kiribati & United Kingdom \\
\hline 1960 & Congo & France & 1979 & Saint Lucia & United Kingdom \\
\hline 1960 & Congo (Dem. Rep. of the) & Belgium and Luxembourg & 1979 & Saint Vincent and the Grenadines & United Kingdom \\
\hline 1960 & Cte d'Ivoire & France & 1980 & Vanuatu & France \\
\hline 1960 & Gabon & France & 1980 & Zimbabwe & United Kingdom \\
\hline 1960 & Madagascar & France & 1981 & Antigua and Barbuda & United Kingdom \\
\hline 1960 & Mali & France & 1981 & Belize & United Kingdom \\
\hline 1960 & Mauritania & France & 1983 & Saint Kitts and Nevis & United Kingdom \\
\hline 1960 & Niger & France & 1984 & Brunei Darussalam & United Kingdom \\
\hline 1960 & Nigeria & United Kingdom & 1986 & Marshall Islands & United States of America \\
\hline 1960 & Senegal & France & 1986 & Micronesia (Federated States of) & United States of America \\
\hline 1960 & Somalia & Italy & 1990 & Lithuania & Russian Federation \\
\hline 1960 & Togo & France & 1990 & Namibia & South Africa \\
\hline 1961 & Kuwait & United Kingdom & 1991 & Armenia & Russian Federation \\
\hline 1961 & Sierra Leone & United Kingdom & 1991 & Azerbaijan & Russian Federation \\
\hline 1962 & Algeria & France & 1991 & Belarus & Russian Federation \\
\hline 1962 & Burundi & Belgium and Luxembourg & 1991 & Estonia & Russian Federation \\
\hline 1962 & Jamaica & United Kingdom & 1991 & Georgia & Russian Federation \\
\hline 1962 & Rwanda & Belgium and Luxembourg & 1991 & Kazakstan & Russian Federation \\
\hline 1962 & Samoa & New Zealand & 1991 & Kyrgyzstan & Russian Federation \\
\hline 1962 & Trinidad and Tobago & United Kingdom & 1991 & Latvia & Russian Federation \\
\hline 1962 & Uganda & United Kingdom & 1991 & Moldova, Rep.of & Russian Federation \\
\hline 1963 & Kenya & United Kingdom & 1991 & Slovenia & Yugoslavia \\
\hline 1963 & Singapore & United Kingdom & 1991 & Tajikistan & Russian Federation \\
\hline 1964 & Malawi & United Kingdom & 1991 & Turkmenistan & Russian Federation \\
\hline 1964 & Malta & United Kingdom & 1991 & Ukraine & Russian Federation \\
\hline 1964 & Tanzania & United Kingdom & 1991 & Uzbekistan & Russian Federation \\
\hline 1964 & Zambia & United Kingdom & 1993 & Eritrea & Ethiopia \\
\hline 1965 & Gambia & United Kingdom & 1994 & Palau & United States of America \\
\hline 1965 & Maldives & United Kingdom & 1995 & Bosnia and Herzegovina & Yugoslavia \\
\hline 1966 & Barbados & United Kingdom & 1997 & Hong Kong & United Kingdom \\
\hline 1966 & Botswana & United Kingdom & 1999 & Macao & Portugal \\
\hline
\end{tabular}

The table lists the countries that became independent after 1939, with their respective metropole. 


\section{References}

Anderson, J. E. and E. Van Wincoop (2003). Gravity with gravitas: a solution to the border puzzle. the american economic review 93(1), 170-192.

Anderson, J. E. and Y. V. Yotov (2010). The changing incidence of geography. The American economic review $100(5), 2157-2186$.

Autor, D. H., D. Dorn, and G. H. Hanson (2013). The china syndrome: Local labor market effects of import competition in the united states. The American Economic Review 103(6), $2121-2168$.

Baier, S. L. and J. H. Bergstrand (2007). Do free trade agreements actually increase members' international trade? Journal of international Economics 71(1), 72-95.

Baldwin, R. and D. Taglioni (2007). Trade effects of the euro: A comparison of estimators. Journal of Economic Integration, 780-818.

Berger, D., W. Easterly, N. Nunn, and S. Satyanath (2013). Commercial imperialism? political influence and trade during the cold war. The American Economic Review 103(2), 863-896.

Berthou, A. and H. Ehrhart (2014). Trade networks and colonial trade spillovers.

Carrere, C. (2006). Revisiting the effects of regional trade agreements on trade flows with proper specification of the gravity model. European Economic Review 50(2), 223-247.

Chaney, T. (2014). The network structure of international trade. The American Economic Review 104(11), 3600-3634.

Cipollina, M. and L. Salvatici (2010). Reciprocal trade agreements in gravity models: A metaanalysis. Review of International Economics 18(1), 63-80.

Costinot, A. and A. Rodríguez-Clare (2013). Trade theory with numbers: Quantifying the consequences of globalization, vol. 4 of handbook of international economics.

De Sousa, J. and J. Lochard (2012). Trade and colonial status. Journal of African Economies 21(3), 409-439.

Disdier, A.-C. and K. Head (2008). The puzzling persistence of the distance effect on bilateral trade. The Review of Economics and statistics 90(1), 37-48.

Feenstra, R. C., J. R. Markusen, and A. K. Rose (2001). Using the gravity equation to differentiate among alternative theories of trade. Canadian Journal of Economics/Revue canadienne d'économique 34(2), 430-447. 
Felbermayr, G. J. and F. Toubal (2010). Cultural proximity and trade. European Economic Review 54(2), 279-293.

Fuchs, A. and N.-H. Klann (2013). Paying a visit: The dalai lama effect on international trade. Journal of International Economics 91(1), 164-177.

Glick, R. and A. K. Rose (2002). Does a currency union affect trade? the time-series evidence. European Economic Review 46(6), 1125-1151.

Glick, R. and A. M. Taylor (2010). Collateral damage: Trade disruption and the economic impact of war. The Review of Economics and Statistics 92(1), 102-127.

Head, K. and T. Mayer (2014). Gravity equations: Workhorse, toolkit, and cookbook, ch. 3 in handbook of international economics, gopinath, g, e. helpman and k. rogoff (eds), vol. 4, 131-95.

Head, K., T. Mayer, and J. Ries (2010). The erosion of colonial trade linkages after independence. Journal of international Economics 81(1), 1-14.

Keller, W., B. Li, and C. H. Shiue (2013). Shanghai's trade, china's growth: continuity, recovery, and change since the opium wars. IMF Economic Review 61(2), 336-378.

Lavallée, E. and J. Lochard (2015). The comparative effects of independence on trade. Journal of Comparative Economics 43(3), 613-632.

Lewer, J. J. and H. Van den Berg (2007). Estimating the institutional and network effects of religious cultures on international trade. Kyklos 60(2), 255-277.

Limão, N. (2016). Preferential trade agreements. Technical report, National Bureau of Economic Research.

Melitz, J. and F. Toubal (2014). Native language, spoken language, translation and trade. Journal of International Economics 93(2), 351-363.

Mitchener, K. J. and M. Weidenmier (2008). Trade and empire. The Economic Journal 118(533), 1805-1834.

Nitsch, V. (2007). State visits and international trade. The World Economy 30(12), 1797-1816.

Rauch, J. E. (2001). Business and social networks in international trade. Journal of economic literature, 1177-1203.

Rose, A. K. (2000). One money, one market: the effect of common currencies on trade. Economic policy 15(30), 08-45. 
Rose, A. K. (2004). Do we really know that the wto increases trade? The American Economic Review 94(1), 98-114.

Silva, J. S. and S. Tenreyro (2006). The log of gravity. The Review of Economics and statistics 88(4), 641-658.

Silva, J. S. and S. Tenreyro (2010). Currency unions in prospect and retrospect. Annu. Rev. Econ 2, 51-74.

Storesletten, K. and F. Zilibotti (2014). Chinas great convergence and beyond. Annu. Rev. Econ. 6(1), 333-362.

Subramanian, A. and S.-J. Wei (2007). The wto promotes trade, strongly but unevenly. Journal of international Economics 72(1), 151-175.

Tinbergen, J. (1962). Shaping the world economy; suggestions for an international economic policy. Books (Jan Tinbergen). 